ARTICLE

\title{
Exceptionally preserved early Cambrian bilaterian developmental stages from Mongolia
}

\author{
Michael Steiner (1) ${ }^{1,2}$, Ben Yang ${ }^{3}$, Simon Hohl ${ }^{4}, \mathrm{Da} \mathrm{Li}^{5} \&$ Philip Donoghue (i) ${ }^{6 凶}$
}

Fossilized invertebrate embryonic and later developmental stages are rare and restricted largely to the Ediacaran-Cambrian, providing direct insight into development during the emergence of animal bodyplans. Here we report a new assemblage of eggs, embryos and bilaterian post-embryonic developmental stages from the early Cambrian Salanygol Formation of Dzhabkan Microcontinent of Mongolia. The post-embryonic developmental stages of the bilaterian are preserved with cellular fidelity, possessing a series of bilaterally arranged ridges that compare to co-occurring camenellan sclerites in which the initial growth stages retain the cellular morphology of modified juveniles. In this work we identify these fossils as early post-embryonic developmental stages of camenellans, an early clade of stembrachiopods, known previously only from isolated sclerites. This interpretation corroborates previous reconstructions of camenellan scleritomes with sclerites arranged in medial and peripheral concentric zones. It further supports the conjecture that molluscs and brachiopods are descended from an ancestral vermiform and slug-like bodyplan.

\footnotetext{
${ }^{1}$ College of Earth Science and Engineering, Shandong University of Science and Technology, Qingdao, China. ${ }^{2}$ Department of Earth Sciences, Freie Universität Berlin, Berlin, Germany. ${ }^{3}$ MNR Key Laboratory of Stratigraphy and Palaeontology, Institute of Geology, Chinese Academy of Geological Sciences, Beijing, China. ${ }^{4}$ State Key Laboratory of Marine Geology, School of Ocean and Earth Sciences, Tongji University, Shanghai, China.

${ }^{5}$ School of Marine Science and Engineering, Nanjing Normal University, Nanjing, China. ${ }^{6}$ School of Earth Sciences, University of Bristol, Bristol, UK.

凶email: Michael.Steiner@FU-Berlin.de; Phil.Donoghue@bristol.ac.uk
} 
T he origin and early evolution of animals is among the most formative episodes in Earth history, establishing the basis of modern animal biodiversity and, through their ecological expansion, precipitating a fundamental change to the Earth system ${ }^{1}$. Animal bodyplans emerged as a consequence of evolutionary changes in the genetic regulation of embryological development. Insights into developmental evolution are usually sought in comparative developmental biology but, surprisingly, the fossil record has begun to provide more direct insights, manifest as fossilized eggs, embryos, and larvae of marine invertebrates ${ }^{2,3}$. Existing reports include almost complete cnidarian life cycles $^{2,4,5}$, a possible ctenophore embryo ${ }^{6}$, scalidophoran embryos, and larvae ${ }^{7-10}$, as well as possible mollusc embryos $^{4}$ which have impacted on macroevolutionary theories of developmental model, life history strategy, as well as the evolution of bodyplan symmetry ${ }^{3}$. The influence of this dimension of the fossil record is strictly limited by a paucity of sites where they are preserved. So far, early developmental stages of invertebrates in Orsten-type preservation have been reported from the Ediacaran to Ordovician of South China, Australia, Laurentia, and Siberia ${ }^{2-4,7,11-15}$.

Here, we report a new assemblage from the Cambrian Stage 3 of the Mongolian Dzhabkan Microcontinent, that includes fossil eggs, embryos attributable to the early scalidophoran Markuelia and, in particular, microscopic bilaterian postembryonic developmental stages preserved to an almost unparalleled cellular fidelity. The juveniles may represent early stages in the life cycle of co-occurring tommotiids, such as Camenella mongolica and Camenella parilobata, in which case they would appear to corroborate the hypothesis of slug-like bodyplan for stembrachiopods ${ }^{16-23}$ and, possibly, ancestral trochozoans.

\section{Results}

An exceptional new Orsten-type fossil deposit of Mongolia. The new assemblage of phosphatized eggs, embryos, and juveniles from Mongolia was discovered in the topmost phospholithoclastic carbonates of the Salanygol Formation at Salanyi Gorge (GPS N46 $48^{\prime} 32.1^{\prime \prime}$ E095 ${ }^{\circ} 46^{\prime} 18.8^{\prime \prime}$ ) located at the Dzhabkan Microcontinent (Fig. 1). The Ediacaran-early Cambrian transition sequence exposed in the Salanyi Gorge of Khasagt Khirekhan Mountain Range (Altai Province) is $>1500$ $\mathrm{m}$ thick ${ }^{24,25}$. This outcrop of the Terreneuvian Bayan Gol Formation exposes a $>1140 \mathrm{~m}$ sequence of thick siliciclastics interlayered with thinner limestones or calcareous bioherms, overlain by massive limestones of the Salanygol Formation (ca. $360 \mathrm{~m}$ thick). The upper $160 \mathrm{~m}$ of the Salanygol Formation commonly contains redeposited archaeocyathans, while the lower part is a monotonous algal limestone devoid of a fossil fauna. Three thin horizons within the topmost $5 \mathrm{~m}$ of the Salanygol Formation contain phosphatized eggs, embryos, and postembryonic articulated life stages (Figs. 2-4), co-occurring with small shelly fossils (SSFs), such as Lapworthella tortuosa, C. mongolica, C. parilobata, Salanygolina obliqua, Khairkhania rotata, Latouchella gobiica, Obtusoconus brevis, Yochelsonella crassa, chancelloriids, and phospatized archaeocyathan fragments. The new deposit of phosphatized Orsten-type fossils is the first reported from the diverse Mongolian terrains of the Central Asian Orogeny Belt (CAOB). This fossil deposit is exceptional for preserving eggs, embryos, and cuticularized articulated organisms (Fig. 2). However, it is unusual for this type of fossil lagerstätte in preserving the cellular structure of tissues (Fig. 4) without extracellular cuticle or fertilization membranes.

The age of the Salanygol Formation has been the subject of some controversy ${ }^{25,26}$, alternately interpreted as Tommotian based on chemostratigraphy and a general lack of trilobites ${ }^{25}$, or Atdabanian-Botoman based on archaeocyathan and SSF assemblages ${ }^{26-28}$. The negative carbon isotopic shift in the lower Salanygol Formation coincides with a transition from boundstones with a higher amount of microbially derived fabrics to limestones with a higher portion of transported archaeocyathan bioclasts ${ }^{29}$. This may suggest that the carbon isotope shift in the Salanygol Formation does not reflect a global open seawater signature but, rather, a regional change in aquafacies, making it less informative stratigraphically. The most reliable age determination for the Salanygol Formation is therefore based on the occurrence of the archaeocyathans Gordonicyathus howelli and Alataucyathus jaroschevitschi ${ }^{28}$ both of which are typical for assemblages of the Altai-Sayan folded region of the $\mathrm{CAOB}$, and correlate to the late Atdabanian of the Siberian Regional stratigraphic subdivision ${ }^{30}$. The Salanygol Formation is overlain unconformably by thick sandstones and conglomerates of the Khayrkhan Formation, correlating with the Botoman/Toyonian ${ }^{28}$.

Bilaterian developmental stages preserved with cellular fidelity from Mongolia. Co-occurring with eggs, late-stage embryos of Markuelia (Fig. 2) and disarticulated SSFs we recovered ten concavo-convex, ovoid disc-like fossils (Figs. 3 and 4) which range in size from $200 \times 300 \mu \mathrm{m}$ to $500 \times 700 \mu \mathrm{m}$ (Supplementary Fig. 1), consistently exhibiting six shallow, approximately bilaterally symmetrical, erect to fully imbricated ridges (Figs. 3a, $\mathrm{f}, \mathrm{h}$ and $4 \mathrm{~b}, \mathrm{c}$ ); we interpret the ridged surface as dorsal, the imbrication of the ridges to reflect anterior-posterior polarity, and size variation to correlate positively with developmental polarity. There is some variation in preservation but the dorsal surfaces of all specimens exhibit an original micromorphology composed of small (7-12 $\mu \mathrm{m}$ diameter) domed polygonal facets (Fig. 3a, b, f, i, 4b, g, f, and 5d). Tomographic data reveal that preservation extends internally (Fig. 4k), with a distinct ventral surface and intervening walls associated with the polygonal borders on the dorsal surface, defining a single polarized layer of cuboidal cellular units. We interpret this as an epithelial cell layer (Fig. 4i-k). None of the specimens preserve additional outer layers covering the cell layer, such as a cuticle or fertilization membrane. The ridges are a development of this dorsal epithelial layer, each ridge V-shaped with an apical spinose projection that is directed posterodorsally. The ridges increase in prominence in correlation with specimen size, reflecting ontogenetic development but also degrees of taphonomic deflation of the ridges (contrast Fig. 3a-h versus Fig. 5b). With only a small number of specimens at hand, it is not yet possible to reconstruct a developmental series. Most preserved individuals represent a similar early developmental stage at a similar size (Supplementary Fig. 1), where the six central Vshaped ridges are still shallow (Figs. 3 and $4 \mathrm{a}-\mathrm{g}$ ). At a later stage, these ridges are more distinct and erect (Figs. $4 \mathrm{~h}$ and $5 \mathrm{~b}$ ). When erect, the medial ridges have a concave anterior and convex posterior surface (Fig. 5b), facilitating the imbrication seen in other specimens (Figs. $3 \mathrm{a}-\mathrm{i}$ and $4 \mathrm{a}-\mathrm{h}$ ). At the anterior pole, a small anterior spinose projection occurs in the smallest specimens, appearing larger in concomitantly larger specimens (Figs. 3a, $\mathrm{f}$ and $4 \mathrm{~b}, \mathrm{e}, \mathrm{h}$ ), and as part of a distinct ridge in one specimen (Fig. 3e, h, i). At the posterior pole, a small distinct ridge occurs in the lee of the sixth major medial ridge (e.g., Fig. $3 c-e)$.

Six pairs of smaller, posteriorly oriented conical protuberances occur at the periphery of the medial ridges in some better preserved individuals. In the smallest specimens, the peripheral protuberances are clustered ventrally, forming a band-like array 


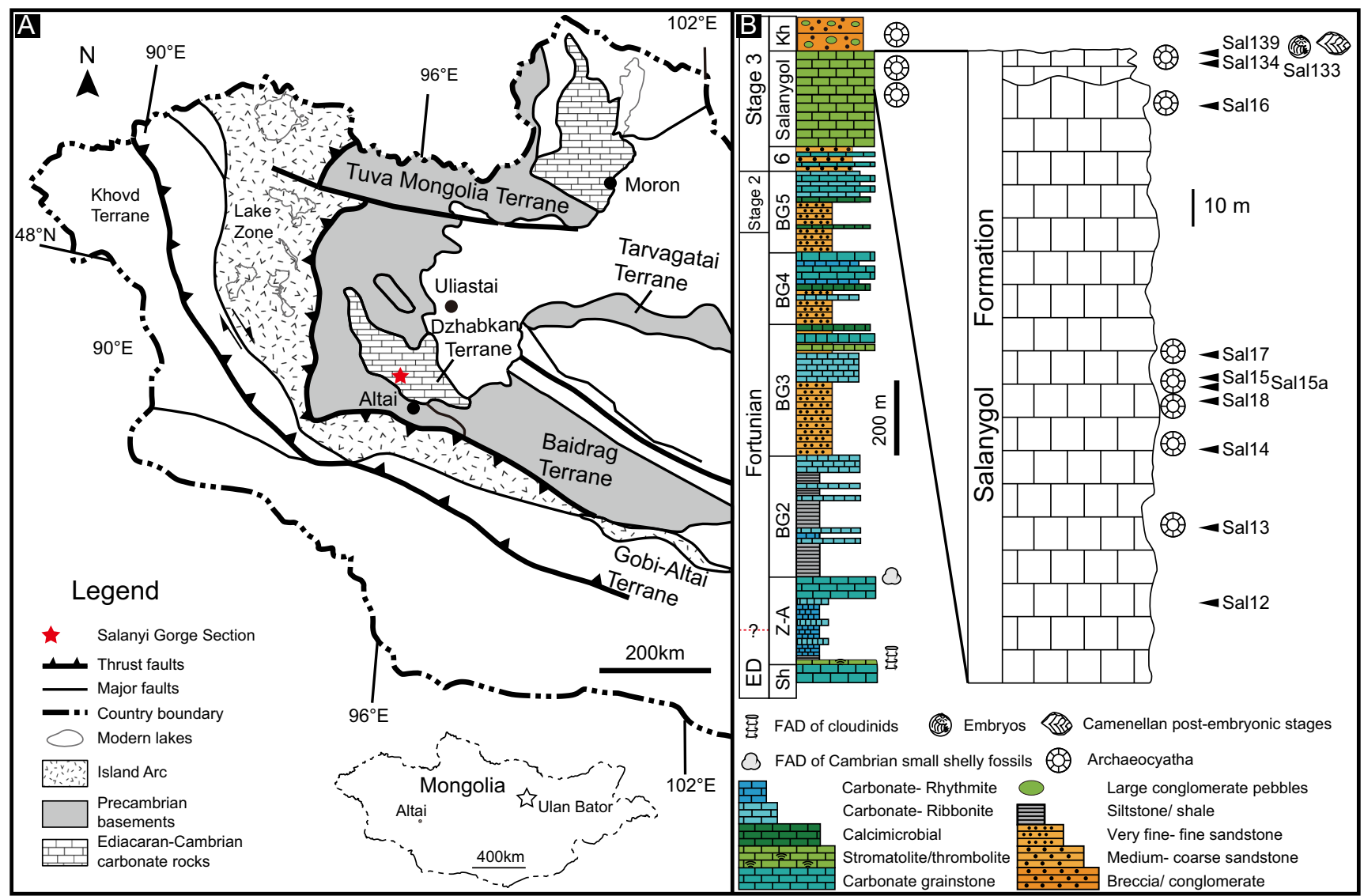

Fig. 1 Geographic and stratigraphic occurrence of new assemblage of embryonic and postembryonic developmental stages. A Locality of Salanyi Gol (Gobi-Altai Province) on Dzhabkan Terrain of Mongolia. B Stratigraphic column (modified from ref. ${ }^{25}$ ) with the distribution of the embryonic and postembryonic developmental stages. ED Ediacaran, Sh Shurgat Formation, Z-A Zuun Arz Formation, BG Bayan Gol Formation (numbers refer to members according ${ }^{25}$ ), Kh Khirekhan Formation, FAD first appearance datum; sample numbers: Sal 139 etc.

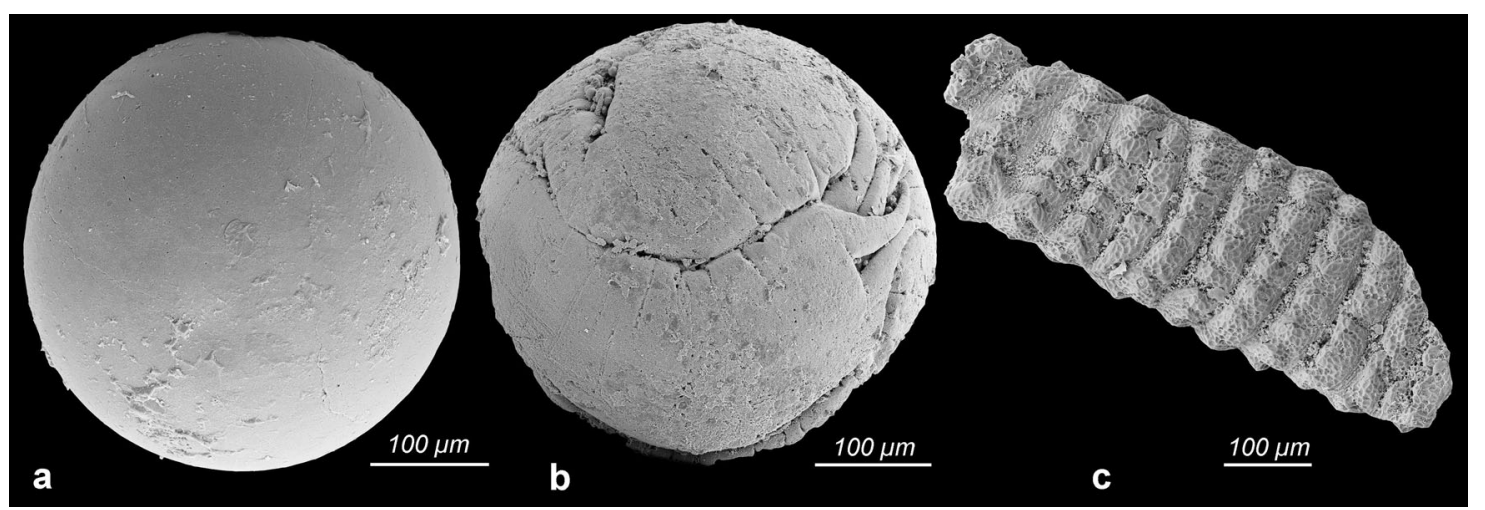

Fig. 2 Phosphatized soft-bodied and cuticularized eggs, embryos, and articulated postembryonic developmental stages of the new Orsten-type fossil lagerstätte Salanyi Gol (Mongolia). a Egg. b Late-stage embryo of Markuelia with six large posterior hooks. c Articulated, hitherto undescribed slug-like organism with rows of cuticularized humps with net-like ornaments. All images are electron microscope micrographs. Specimen identifiers: a Sal 134-38; b Sal 134-16; c Sal 134-28.

of distinct fields (Fig. 4d); the ventral dome-shaped concavity is not exposed. In larger specimens, the ventral surface is otherwise dominated by a concavity elongated along the anterior-posterior axis, with a limiting circumferential ridge which extends ventral of the paired peripheral ridges (Fig. 3c), tapering to the position of the anterior spine. Together, these features comprise a total of 18 bilaterally arranged structures; six medial ridges and six pairs of marginal conical protuberances, all of which we consider as nascent sclerites.

\section{Discussion}

Affinity of the early postembryonic bilaterian developmental stages. The polarized bilateral symmetry and dorsoventrally differentiated organization of these demonstrably multicellular fossil organisms is compatible only with a total-group bilaterian animal affinity. The exposed cellular epithelial organization of the dorsal surface is strongly reminiscent of embryonic stages of animal development, in which a protective integument has yet to develop. However, the size range of the developmental stages is 


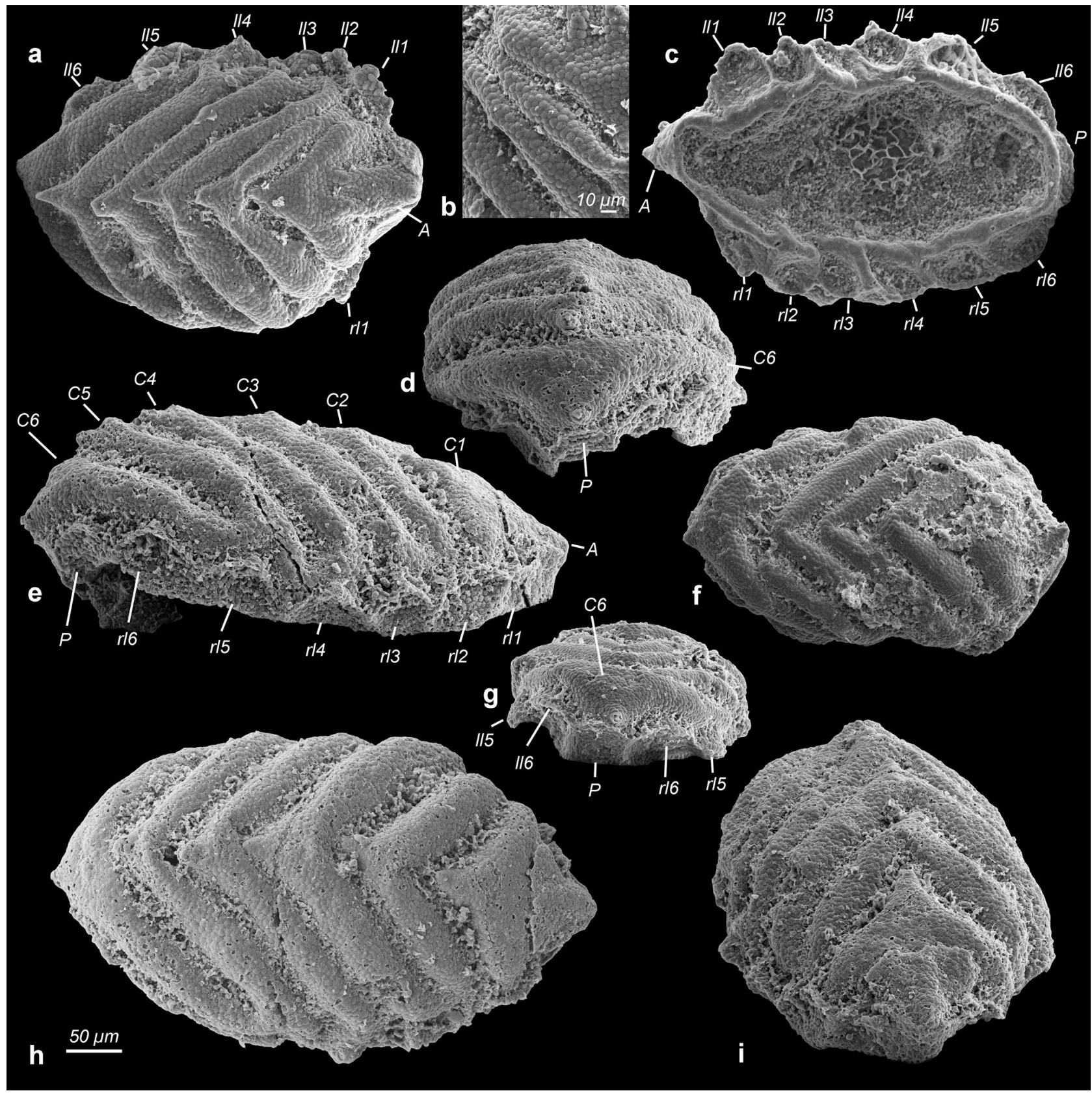

Fig. 3 Camenellan juveniles from the Cambrian Salanygol Formation of Mongolia. a Dorsal view of an early juvenile with six arc-shaped ridges preserving cellular pattern; anterior nascent sclerite with different morphology. b Close-up of central ridges C1-3 with cellular pattern, enlargement of individual shown in a. c Ventral view of the early juvenile shown in $\mathbf{a}$, with six pairs of lateral protuberances. $\mathbf{d}$ Posterior view, posterior nascent sclerite forms a small field only in this ontogenetic stage. e Lateral view on right peripheral zone with six small lateral protuberances. $\mathbf{f}$ Dorsal view of an individual with shallow central ridges. $\mathbf{g}$ Posterior view, note left lateral nascent sclerite five forms an asymmetric cone. $\mathbf{h}$ Dorsal view of an early juvenile with six arc-shaped central ridges. $\mathbf{i}$ Anterior view of $\mathbf{h}$ showing anterior nascent sclerite developing a different morphology than central nascent sclerites 1-6. C1-6 central nascent sclerite 1-6 of medial zone, P posterior nascent sclerite, A anterior nascent sclerite, II1-6 left lateral sclerites 1-6 of peripheral zone, rl1-6 right lateral nascent sclerites 1-6 of peripheral zone. All images are electron microscope micrographs, all images at same scale except for $\mathbf{b}$. Specimen identifiers: a-d Sal 139-019; e, h, i Sal 133-029; f, g Sal 133-43.

indicative of growth, which only occurs in post-hatching stages (Supplementary Fig. 1). Moreover, while associated eggs and embryos of Markuelia are mostly preserved with fertilization envelopes, the new bilaterian fossils are not, indicating that they represent postembryonic developmental stages. The fossils are not completely preserved; there must have been more to the softtissue anatomy of this organism than the epithelial layer comprising the dorsum. The ventral concavity must represent the location of the main corpus of the organism. There is little direct evidence to constrain ventral anatomy, but body orifices, locomotory, and sensory organs must have been directed ventrally since, given the cellular fidelity of preservation, they would be observable if present dorsally. This anatomical interpretation is compatible with a slug-like bodyplan comparable to those of the acuiliferan molluscs, including crown-polyplacophorans, stempolyplacophorans such as Echinochiton ${ }^{31}$, and stem-acuiliferans such as Halkieria ${ }^{32}$ and Calvapilosa ${ }^{33}$. Indeed, the morphology of the central ridges is reminiscent of the early development of 


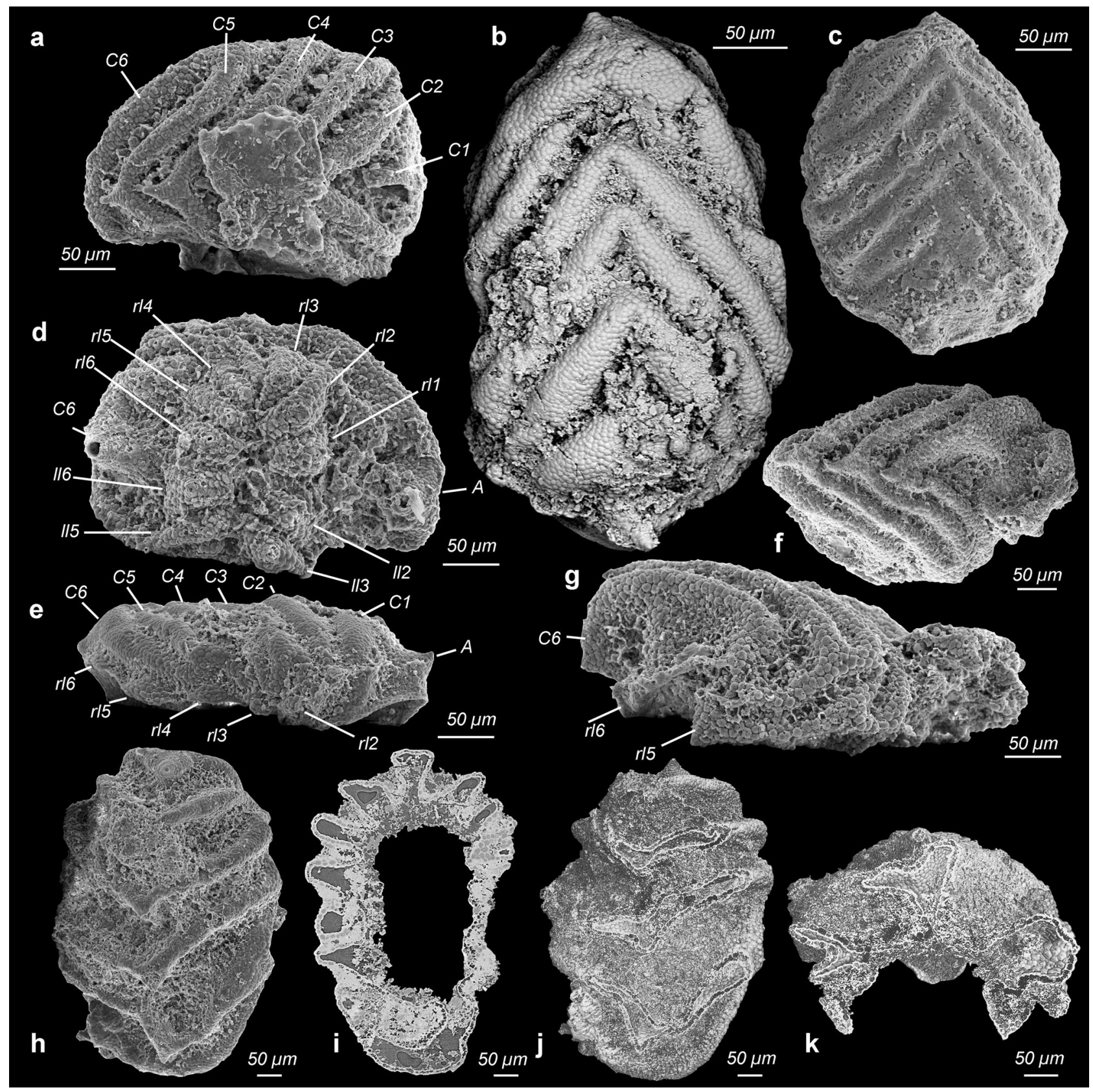

Fig. 4 Camenellan juveniles from the Cambrian Salanygol Formation of Mongolia. a Dorsal view of an early juvenile with six central ridges preserving cellular pattern. $\mathbf{b}$ Dorsal view of the juvenile stage with six arc-shaped central ridges and one differently shaped anterior spinose structure. $\mathbf{c}$ Dorsal view of a juvenile with six shallow central ridges and an anterior field with a different morphology. $\mathbf{d}$ Ventral view of juvenile stage illustrated in $\mathbf{a}$; 12 distinct fields form a band-like array in this ontogenetic stage, which later develop into the peripheral zone; note the circular plate-like anterior nascent sclerite with a small projection is outside the ventral band of fields; a posterior nascent sclerite is not yet developed or detectable. e Lateral view of an individual shown in b with shallow central ridges and the anterior nascent sclerite visible as an erect broad spine, lateral nascent sclerites are still not yet well developed, forming small fields at the bases of central ridges. $\mathbf{f}$ Slightly distorted and incomplete early juvenile with well-preserved cellular pattern. $\mathbf{g}$ Lateral view of incomplete early juvenile illustrated in $\mathbf{f}$, where lateral protuberances begin to develop as asymmetric cones. $\mathbf{h}$ Larger juvenile with central ridges beginning to develop more erect structures. $\mathbf{i}$, $\mathbf{j}$ Half volumes at different dorsoventral cutting planes of syncCT-models of individual shown in $\mathbf{h}$, note single epithelial cell layer in sectioning plane. $\mathbf{k}$ Half volume of syncCT-model of $\mathbf{h}$ with cutting plan in anterior-posterior direction, revealing similar cellular pattern on the ventral side as visible dorsally. C1-6 central nascent sclerite 1-6 of medial zone, P posterior nascent sclerite, A anterior nascent sclerite, II1- 6 left lateral sclerites 1-6 of peripheral zone, rl1-6 right lateral nascent sclerites 1-6 of peripheral zone. All images are secondary electron micrographs of an electron microscope, except for $\mathbf{b}$, which is a backscatter electron micrograph and $\mathbf{i}-\mathbf{k}$, which are volume models of X-ray syncCT. Specimen identifiers: $\mathbf{a}$, $\mathbf{d}$ Sal 133040; b, e Sal 133-43, c Sal 139-012; g, f Sal 133-042; h-k Sal 133-044.

sclerites in modern chitons ${ }^{34}$, where distensions in the soft tissue of the trochophora larva and the earliest hatchlings represent the precursor of biomineralized plates in the juveniles. However, the overall morphology is also compatible with stem-molluscs such as Wiwaxia ${ }^{35}$, as well as more enigmatic taxa such as Orthozanclus $^{36}$ and Paracarinachites ${ }^{37}$, and it is the inferred bodyplan of putative early stem-brachiopods, such as the camenellan tommotiids ${ }^{16-23,36,38,39}$. 
NATURE COMMUNICATIONS | https://doi.org/10.1038/s41467-021-21264-7

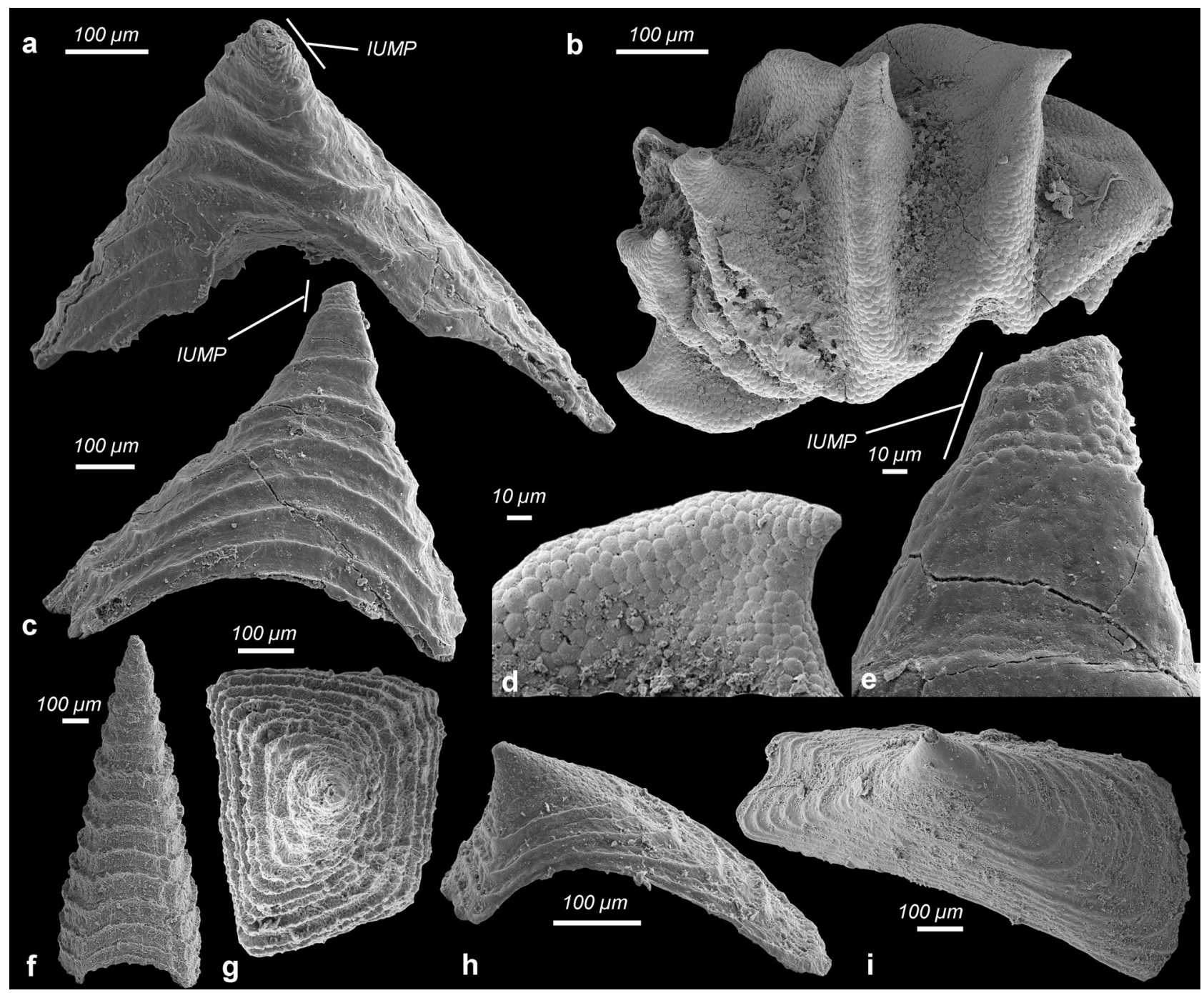

Fig. 5 Camenellan juvenile and disarticulated tommotiid sclerites from the Cambrian Salanygol Formation of Mongolia. a, c Anterior and posterior views of disarticulated saddle-shaped sclerites of $C$. mongolica co-occurring with camenellan juvenile; note the partly broken tip preserves cellular pattern only visible in the juvenile part, but not in biomineralized parts with co-marginal ribs. b Dorsal view of an incomplete camenellan juvenile with six central erect spinose nascent sclerites; note cellular pattern still preserved on whole dorsum. $\mathbf{d}$ Detail of cellular pattern in a central nascent sclerite $\mathrm{C} 1$ of camenellan juvenile prior to onset of biomineralization, enlargement from $\mathbf{b}$. e Detail of cellular pattern in the juvenile part of $C$. mongolica shown in c; note phosphate biomineralization covered cells with formation of co-marginal ribs. $\mathbf{f}$ Lateral view of an almost symmetrical sclerite of $C$. mongolica. $\mathbf{g}$ Apical view of $\mathbf{f}$. $\mathbf{h}$ Lateral view of an asymmetrical sclerite of $C$. mongolica and four co-marginal ridges. i Oblique view of an almost symmetrical sclerite of $C$. mongolica with a central fold ("sella"). All images are electron microscope micrographs. IUMP initial primarily unbiomineralized part of the early postembryonic developmental stage of Camenella. Specimen identifiers: a, c, e Sal 133-023; b, d Sal 134-05; f, g Sal 121-10; h Sal 133-10; i Sal 133-24.

Most of these comparisons are very general and amount to little more than the vicarious slug-like gestalt. These juveniles clearly lack the shell plates of stem- and crown-acuiliferans, which is presumably a juvenile feature of sachitids. They also exhibit a simpler organization than the complex sclerotome of sachitids, Orthozanclus and Wiwaxia. Paracarinachites is also difficult to rationalize with the anatomy of the new fossils, not least since its serial organization reflects marginal sequential addition to the scleritome, not an initially metameric organization. Furthermore, we did not recover remains of these groups in our samples, some of which are known only from much older ${ }^{37}$ and younger ${ }^{31}$ strata. However, the morphology of the broad-based medial ridges and their apical spines in the unmineralized juvenile is particularly reminiscent of the mineralized sclerites of co-occurring sclerites attributed to Camenella (Fig. 5a, c, f-i). Furthermore, the isolated sclerites of Camenella in this assemblage preserve at their tips a pattern of epithelial cell imprints comparable to the dorsal epithelium of these juvenile stages (Fig. 5a, c, e). We therefore propose that these bilaterian fossils represent early postembryonic developmental stages of co-occurring camenellans, and that the ridges and conical protuberances on their dorsal surface reflect an early nonskeletal stage in the morphogenesis of camenellan sclerites which developed from this epithelium. We consider these early postembryonic developmental stages because of the morphological and structural changes required in establishing the adult bauplan of camenellans. These include further differentiation into three discrete types of sclerites, the development of co-marginal ribbing on the sclerites and, in particular, the onset of biomineralization.

The number of ridges and conical protuberances in the dorsal surface of the bilaterian postembryonic developmental stages suggests that early in its development, the scleritome was composed of 20 sclerites arranged in two zones, a medial zone with more symmetrical sclerites (albeit often with slight asymmetry or torsion in mineralized sclerites of adults) and a 
peripheral zone with strongly asymmetric sclerites (Fig. 6). As such, we recognize three different types of sclerites in the scleritome instead of two interpreted by Bengtson ${ }^{16}$ and Skovsted et al. ${ }^{38}$ for Camenella: (a) six large saddle-shaped central sclerites (Fig. 5f, g), (b) one broader and spinose anterior sclerite and a small posterior sclerite (Fig. 5i), as well as (c) six pairs of strongly

a. Camenellan early post-embryonic stage

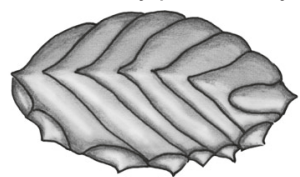

b. Camenellan later juvenile (hypothetic)

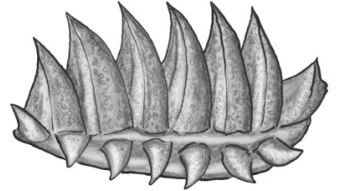

c. Camenellan adult (hypothetic)

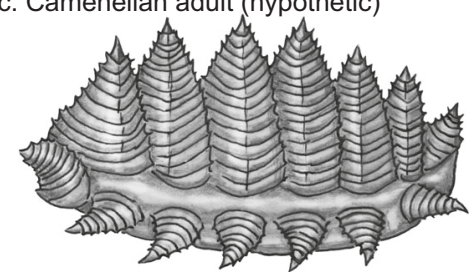

Fig. 6 Reconstruction of dorsal morphology in camenellans. a Interpretative reconstruction of camenellan early postembryonic developmental stage with six central-arched shallow ridges and six pairs of strongly asymmetric lateral protuberances of peripheral zone. b Hypothetical reconstruction of dorsal scleritome in juvenile camenellan before onset of biomineralization in sclerites. c Hypothetical reconstruction of dorsal scleritome in an adult camenellan with biomineralized sclerites organized in a medial and a peripheral concentric zone. asymmetric lateral sclerites (Fig. 5h). The three sclerite morphotypes have already been recognized in the kennardiid Dailyatia ${ }^{39}$ and are likely to occur also in kelanellids, such as Kelanella and Lugoviella.

Camenellans have been known hitherto only from disarticulated sclerites and the nature of their bodyplan and that of other tommotiids, has been the subject of protracted conjecture ${ }^{16-23,38,39}$. They are implicated in debates over the nature of tommotiid bodyplans, the evolutionary assembly of the brachiopod bodyplan, and (almost ironically) utilized as an interpretative model for resolving the affinity of halkieriids. Following Bengtson ${ }^{16}$, the bodyplan of camenellans has invariably been inferred as slug-like, with a multimembrate dorsal scleritome. Bengtson ${ }^{16}$ reconstructed the scleritome as composed of serial transverse rows comprised of a single medial approximately symmetrical mitral sclerite flanked by a pair of asymmetric sellate sclerites. This model was followed in reconstructing the scleritomes of other camanellans (e.g., refs. ${ }^{38,39}$ ) and adapted for other tommotiids ${ }^{16-23}$. Based solely on isolated sclerites, it is astonishing that these reconstructed scleritomes bear any resemblance to reality, let alone the very precise correspondence of the bilaterian postembryonic developmental stages to the original reconstruction of Bengtson ${ }^{16}$. Based on the consistent occurrence of ridges and protuberances in the juveniles, we hypothesize that adult camenellans developed a dorsal scleritome with organophosphatic assymetric sclerites arranged in the peripheral zone of a slug-like body and more symmetrical sclerites in the central medial zone, and with some morphological variation in the anterior position (Fig. 6).

The bilaterian postembryonic developmental stages from the Salanygol Formation suggest that tommotiids manifest diverse bodyplans, adding the slug-like bauplan of camenellans to the tubular bodyplan of eccentrothecan tommotiids ${ }^{40}$, and the bivalved bodyplan inferred for Micrina ${ }^{41}$. Camenellans are commonly accepted as early diverging members of the brachiopod stem lineage $\mathrm{e}^{36,38,42}$.

Camenellans developed a complex dorsal scleritome organized into a medial and peripheral zone (Fig. 6), similar to sachitids with three concentric zones and polyplacophorans with two

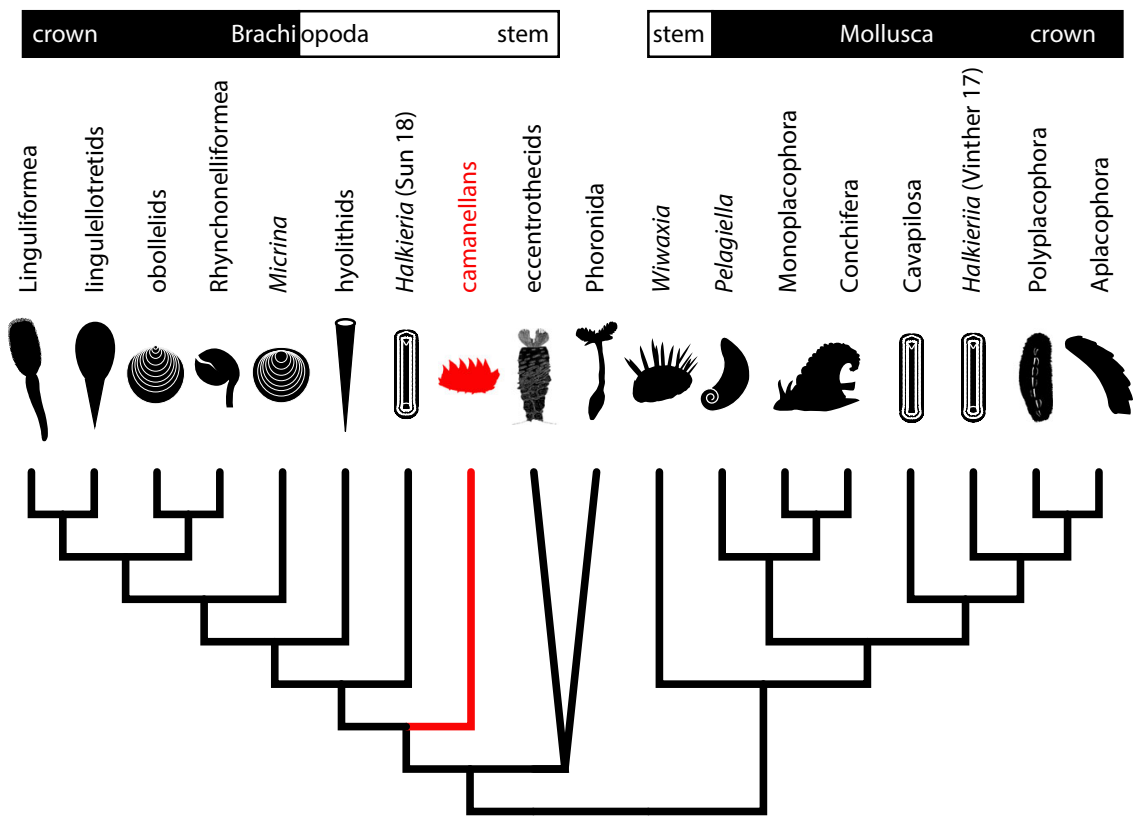

Fig. 7 Phylogenetic position of camenellans and other tommotiid clades among crown-brachiopods, -phoronids, -molluscs, and their respective stem lineages (modified from refs. ${ }^{\mathbf{3 6}, \mathbf{4 2}}$ ). The common ancestor of the molluscan and brachiopod stem-lineages is likely reconstructed as a slug-like vermiform organism with multiple sclerites arranged in concentric zones. The differing phylogenetic positions for Halkieria reflect the contrasting interpretations Vinther et al. ${ }^{33}$ and Sun et al. ${ }^{42}$, while the phylogenetic position of eccentrothecids and phoronids are presented as an unresolved consensus of recent studies $40,42,45$ 
concentric zones. Indeed, Zhao et al. ${ }^{36}$ rejected a sachitid affinity for Halkieria ${ }^{33}$ allying it and Orthozanclus to the camenellans (compare Fig. 7). To them and others ${ }^{43}$, this similarity reflects brachiopods and molluscs having descended from a slug-like common ancestor with a dorsal, serially organized scleritome that may or may not have been biomineralized. They consider but dismiss the challenges of this hypothesis, including the conflicting mineralogies of sachitid and tommotiid sclerites. However, the constructional morphology of camenellan sclerites, marshaled in support of a brachiopod affinity ${ }^{38}$, is not readily compatible with the sclerites of halkieriids, which are more comparable to chiton sclerites ${ }^{44}$. Together, this suggests that though mineralized sclerites may not be a shared primitive feature of a brachiopod plus mollusc clade, a vermiform slug-like bodyplan may well reflect the nature of the common ancestor of these trochozoan phyla (Fig. 7). This conclusion is incompatible with the interpretation of the tubiculous eccentrothecids and phoronids as an outgroup to brachiopods and tommotiids, including camenellans, which has been used to support a tubiculous origin of the bivalved brachiopod bodyplan ${ }^{40,45}$. However, the phylogenetic position of eccentrothecids and phoronids, relative to one another, as well as to other trochozoans, remains highly contentious, with most phylogenetic schemes resolving them as comprising a clade ${ }^{40,45}$, and as closer relatives of crown-brachiopods than camenellans ${ }^{36,45}$. As such, the tubiculous bodyplan of eccentrothecids and phoronids is derived from a slug-like bodyplan. It is worth noting that Camenella and other tommotiid genera are most common in the Cambrian Stage 3, where they co-occur with the oldest crowngroup brachiopods, suggesting some evolutionary prehistory to the brachiopod total group.

An unusual fidelity of preservation in the new Salanygol lagerstätte. Most previous reports of phosphatized invertebrate eggs, embryos and juveniles, and larvae have been documented from cratons with Ediacaran-Cambrian cover strata containing large phosphate deposits, such as the Yangtze Platform ${ }^{7,10-12,14}$ and Australia ${ }^{15,46}$. Reports from strata unaccompanied by sedimentary phosphate deposits, such as Siberia ${ }^{4}$ and Laurentia ${ }^{15}$, are rarer still and largely preserve only embryonic and postembryonic developmental stages in which cuticle develops precociously. This new report from the Cambrian Stage 3 Salanygol Formation of Mongolia is significant in that it is unaccompanied by sedimentary phosphate deposits and yet, alongside the cuticular embryos of Markuelia, embryos encased in extracellular fertilization membrane and articulated cuticularized worm-like organisms (Fig. 2) it preserves uncuticularised early postembryonic developmental stages with a cellular level of fidelity not seen previously outside of sedimentary phosphate deposits. The early Ediacaran Weng'an Biota and the early Cambrian Kuanchuanpu Formation, both on the Yangtze Platform, preserve embryos to a cellular and subcellular level ${ }^{47-49}$, but they do not preserve postembryonic stages with cellular fidelity. This fine scale of preservation is commonly referred to Orsten-style preservation where softbodied remains are replicated through impregnation or templating with calcium phosphate ${ }^{50}$. However, Orsten-style preservation is almost exclusively limited to the preservation of recalcitrant cuticle and gut contents; cellular scale preservation is almost unknown ${ }^{50}$. In this sense, the cellular scale preservation of embryos is quite distinct, attributed to the geochemical microenvironments created by enclosure within a fertilization envelope that inhibits decay and promotes authigenic mineralization ${ }^{51}$. Experimental evidence has suggested that the preservation of uncuticularised juvenile stages 52 is not possible, since they decay rapidly and even when microbial degradation is suppressed, the constituent cells lose cell adhesion and are dispersed ${ }^{51}$. The cellularly preserved early postembryonic developmental stages from the Salanygol Formation demonstrate that these experimental insights are not limiting on the fossil record more generally. They prompt the need for a better experimental understanding of the mechanisms by which cellular scale preservation of developmental stages can be fossilized. The Salanygol assemblage also raises the potential for discovering a greater breadth of life developmental stages from the fossil record, and expands the scope of facies and stratigraphic intervals, in which they may be discovered.

The soft-bodied fauna from the Salanygol Formation preserves an assemblage of phosphatized eggs and late-stage embryos of Markuelia alongside early postembryonic development stages of a slug-like metameric bilaterian. We interpret the bilaterian developmental stages as juveniles of camenellans represented in the same fossil deposit by adult sclerites. As such, the camenellan juveniles appear to corroborate the widely held, but unsubstantiated view that these camenellan tommotiids had a slug-like bodyplan with a dorsal scleritome, perhaps reflecting a slug-like bodyplan for ancestral trochozoans. It is likely that a broader diversity of developmental stages and taxa are preserved within the fossil lagerstätte, whose characteristics raise great hope for comparable discoveries in similar facies from other geographic regions and stratigraphic intervals. These will serve to flesh out our understanding of the embryology of early animals and the emergence of the bodyplans that underpin extant animal biodiversity.

\section{Methods}

The phosphatized embryos, postembryonic developmental stages, and adult sclerites were extracted with $10 \%$ buffered acetic acid from carbonates, followed by sieving $(>64$ and $>125 \mu \mathrm{m})$ and hand-picking of the acid-resistant residue (fraction $>125 \mu \mathrm{m}<2 \mathrm{~mm}$ ) under a binocular microscope. Scanning electron microscopy (SEM) was carried out at the Department of Earth Sciences, Freie Universität Berlin with a ZEISS Supra 40 VP Ultra (Carl Zeiss Microscopy GmbH, Oberkochen, Germany). Specimens selected for investigation in SEM were rinsed in pure ethanol, mounted on aluminum sample stubs with adhesive carbon film, and sputtered for 6 min with gold in a BioRad elemental SEM coating system. Synchrotron Radiation X-ray Tomographic Microscopy ( $\mathrm{srXTM}$ ) was conducted at the X02DA TOMCAT beamline of the Swiss Light Source, Paul Scherrer Institut, Villigen, Switzerland. Measurements were obtained with an operating voltage of $15 \mathrm{KeV}$, exposure of $150 \mathrm{~ms}$, using a $20 \mu \mathrm{m}$ LuAg:Ce scintillator, and a $20 \times$ objective, yielding reconstructed tomographic data with voxel dimensions of $0.325 \mu \mathrm{m}$. A total of 1501 projections were taken equiangularly through $180^{\circ}$ of rotation within the beam. Projections were post-processed and rearranged into flatand dark-field-corrected sinograms, and reconstruction was performed on a 60core Linux PC farm, using a highly optimized routine based on the Fourier transform method and a regridding procedure ${ }^{53}$. Slice data were analyzed and manipulated using VGStudioMax 2.0 (www.volumegraphics.com). Figures were assembled using the computer software Adobe Photoshop CS6, Adobe Illustrator CS6 and Microsoft Ecxel 14.2 for Mac, while texts were handled by Microsoft Word 14.2 for Mac.

Reporting summary. Further information on research design is available in the Nature Research Reporting Summary linked to this article.

\section{Data availability}

Tomographic data are freely available from the University of Bristol Research Data Depository at https://data.bris.ac.uk/data/dataset/27qu5twt57gu62m9dpk4ntcrfs, https:// doi.org/10.5523/bris.27qu5twt57gu62m9dpk4ntcrfs. All figured specimens are housed at the Department of Earth Sciences, Freie Universität Berlin (FUB).

Received: 23 January 2020; Accepted: 6 January 2021; Published online: 15 February 2021

\section{References}

1. Wood, R. et al. Integrated records of environmental change and evolution challenge the Cambrian Explosion. Nat. Ecol. Evolution 3, 528-538 (2019). 
2. Donoghue, P. C. J. \& Dong, X. P. in Evolving Form and Function: Fossils and Development (ed Briggs, D. E. G.) 81-99 (Yale University, 2005).

3. Donoghue, P. C. J., Cunningham, J. A., Dong, X.-P. \& Bengtson, S. in Evolutionary Developmental Biology of Invertebrates Vol. 1: Introduction, Non-Bilateria, Acoelomorpha, Xenoturbellida, Chaetognatha (ed Wanninger, A.) $45-63$ (Springer, 2015)

4. Kouchinsky, A., Bengtson, S. \& Gershwin, L. Cnidarian-like embryos associated with the first shelly fossils in Siberia. Geology 27, 609-612 (1999).

5. Dong, X. P. et al. Embryos, polyps and medusae of the Early Cambrian scyphozoan Olivooides. Proc. R. Soc. Ser. B 280, 20130071 (2013).

6. Chen, J.-Y. et al. Raman spectra of a Lower Cambrian ctenophore embryo from southwestern Shaanxi, China. Proc. Natl Acad. Sci. USA 104, 6289-6292 (2007).

7. Dong, X.-P., Donoghue, P. C. J., Cheng, H. \& Liu, J. Fossil embryos from the Middle and Late Cambrian period of Hunan, south China. Nature 427, 237-240 (2004).

8. Dong, X.-P. et al. The anatomy, taphonomy, taxonomy and systematic affinity of Markuelia: early Cambrian to early Ordovician scalidophorans. Palaeontology 53, 1291-1314 (2010).

9. Zhang, X.-G., Pratt, B. R. \& Shen, C. Embryonic development of a middle Cambrian (500 Myr old) scalidophoran worm. J. Paleontol. 85, 898-903 (2011).

10. Steiner, M., Qian, Y., Li, G., Hagadorn, J. W. \& Zhu, M. The developmental cycles of early Cambrian Olivooidae fam. nov. (?Cycloneuralia) from the Yangtze Platform (China). Palaeogeogr. Palaeoclimatolo. Palaeoecol. 398, 97-124 (2014)

11. Zhang, X. G. \& Pratt, B. R. Middle Cambrian arthropod embryos with blastomeres. Science 266, 637-639 (1994).

12. Xiao, S., Zhang, Y. \& Knoll, A. H. Three-dimensional preservation of algae and animal embryos in a Neoproterozoic phosphorite. Nature 391, 553-558 (1998).

13. Steiner, M., Li, G., Qian, Y. \& Zhu, M. Lower Cambrian small shelly fossils of northern Sichuan and southern Shaanxi (China), and their biostratigraphic importance. Geobios 37, 259-275 (2004).

14. Steiner, M., Zhu, M., Li, G., Qian, Y. \& Erdtmann, B.-D. New early Cambrian bilaterian embryos and larvae from China. Geology 32, 833-836 (2004).

15. Donoghue, P. C. J. et al. Fossilized embryos are widespread but the record is temporally and taxonomically biased. Evol. Dev. 8, 232-238 (2006).

16. Bengtson, S. The Lower Cambrian fossil. Tommotia. Lethaia 3, 363-392 (1970).

17. Conway Morris, S. \& Chen, M. Tommotiids from the Lower Cambrian of South China. J. Paleontol. 64, 169-184 (1990).

18. Ushatinskaya, G. T. in The Cambrian biostratigraphy of the Stansbury Basin, South Australia (eds Alexander, E. M., Jago, J. M., Rozanov, A. Y. \& Zhuravlev, A. Y.) 117-120 (IAPC Nauka/Interperiodica, 2001).

19. Ushatinskaya, G. T. Genus Micrina (small shelly fossils) from the Lower Cambrian of South Australia: morphology, microstructures, and possible relation to halkieriids. Paleontol. Zh. 36, 9-19 (2002).

20. Holmer, L. E. in Brachiopods ancient and modern: A tribute to G. Arthur Cooper. The Palaeontological Society Papers 7 (eds Carlson, S. J. \& Sandy, M. R.) 11-26 (The Paleontological Society, 2001).

21. Holmer, L. E., Skovsted, C. B. \& Williams, A. A stem group brachiopod from the Lower Camrbian: support for a Micrina (halkieriid) ancestry. Palaeontology 45, 875-882 (2002).

22. Williams, A. \& Holmer, L. E. Shell structure and inferred growth, function and affinities of the sclerites of the problematic Micrina. Palaeontol. 45, 845-873 (2002).

23. Li, G. \& Xiao, S. Tannuolina and Micrina (Tannuolinidae) from the Lower Cambrian of eastern Yunnan, South China, and their scleritome reconstruction. J. Paleontol. 75, 900-913 (2004).

24. Brasier, M. D., Shields, G., Kuleshov, V. N. \& Zhegallo, E. A. Integrated chemo- and biostratigraphic calibration of early animal evolution: Neoproterozoic - early Cambrian of southwest Mongolia. Geol. Mag. 133, 445-485 (1996).

25. Smith, E. F., Macdonald, F. A., Petach, T. A., Bold, U. \& Schrag, D. P. Integrated stratigraphic, geochemical, and paleontological late Ediacaran to early Cambrian records from southwestern Mongolia. Geol. Soc. Am. Bull. 128, 442-468 (2016).

26. Landing, E. \& Kruse, P. D. Integrated stratigraphic, geochemical, and paleontological late Ediacaran to early Cambrian records from southwestern Mongolia: Comment. GSA Bull. 129, 1012-1015 (2017).

27. Esakova, N. V. \& Zhegallo, E. A. in Biostratigraphy and Fauna of Lower Cambrian of Mongolia (Nauka, 1996).

28. Kruse, P. D., Gandin, A., Debrenne, F. \& Wood, R. A. Early Cambrian bioconstructions in the Zavkhan Basin of western Mongolia. Geol. Mag. 133, 429-444 (1996).

29. Cordie, D. R., Dornbos, S. Q., Marenco, P. J., Oji, T. \& Gonchigdorj, S. Depauperate skeletonized reef-dwelling fauna of the early Cambrian: Insights from archaeocyathan reef ecosystems of western Mongolia. Palaeogeogr. Palaeoclimatol. Palaeoecol. 514, 206-221 (2019).

30. Sosnovskaja, O. V., Tokarev, D. A. \& Korovnikov, I. V. The regional stratigraphic chart for the lower Cambrian of the eastern part of the AltaiSayan Folded Area. Geol. Miner. Resour. Sib. 8c, 33-68 (2019).

31. Pojeta, J. Jr \& DuFoe, J. New information about Echinochiton dufoei, the Ordovician spiny chiton. Am. Malacol. Bull. 25, 25-34 (2008).

32. Vinther, J. \& Nielsen, C. The early Cambrian Halkieria is a mollusc. Zoologica Scr. 34, 81-89 (2005)

33. Vinther, J., Parry, L., Briggs, D. E. \& Van Roy, P. Ancestral morphology of crown-group molluscs revealed by a new Ordovician stem aculiferan. Nature 542, 471-474 (2017).

34. Lord, J. P. Larval development, metamorphosis and early growth of the gumboot chiton Cryptochiton stelleri (Middendorff, 1847) (Polyplacophora: Mopaliidae) on the Oregon coast. J. Mollusca. Stud. 77, 182-188 (2011)

35. Smith, M. R. \& Lane, P. Ontogeny, morphology and taxonomy of the soft-bodied Cambrian 'mollusc' Wiwaxia. Palaeontology 57, 215-229 (2014).

36. Zhao, F. et al. Orthrozanclus elongata n. sp. and the significance of sclerite-covered taxa for early trochozoan evolution. Sci. Rep. 7, 16232 (2017).

37. Qian, Y. \& Bengtson, S. Palaeontology and biostratigraphy of the Early Cambrian Meishucunian Stage in Yunnan Province, South China. Foss. Strat. 24, 1-156 (1989).

38. Skovsted, C. B., Balthasar, U., Brock, G. A. \& Paterson, J. R. The tommotiid Camenella reticulosa from the Early Cambrian of South Australia: morphology, scleritome reconstruction, and phylogeny. Acta Palaeontol. Pol. 54, 525-540 (2009).

39. Skovsted, C. B., Betts, M. J., Topper, T. P. \& Brock, G. A. The early Cambrian tommotiid genus Dailyatia from South Australia. Mem. Assoc. Australas. Palaeontol. 48, 1-117 (2015).

40. Skovsted, C. B., Brock, G. A., Paterson, J. R., Holmer, L. E. \& Budd, G. E. The scleritome of Eccentrotheca from the Lower Cambrian of South Australia: Lophophorate affinities and implications for tommotiid phylogeny. Geology 36, 171-174 (2008)

41. Holmer, L. E., Skovsted, C. B., Brock, G. A., Valentine, J. L. \& Paterson, J. R The Early Cambrian tommotiid Micrina, a sessile bivalved stem group brachiopod. Biol. Lett. 4, 724-728 (2008).

42. Sun, H. et al. Hyoliths with pedicles illuminate the origin of the brachiopod body plan. Proc. R. Soc. Ser. B 285, 20181780 (2018).

43. Conway Morris, S. \& Peel, J. S. Articulated halkieriids from the Lower Cambrian of North Greenland and their role in early protostome evolution. Philos. Trans. R. Soc. Lond. Ser. B 347, 305-358 (1995).

44. Vinther, J. The canal system in sclerites of Lower Cambrian Sinosachites (Halkieriidae: Sachitida): significance for the molluscan affinities of the sachitids. Palaeontology 52, 689-712 (2009).

45. Skovsted, C. B., Brock, G. A., Topper, T. P., Paterson, J. R. \& Holmer, L. E. Scleritome construction, biofacies, biostratigraphy and systematics of the tommotiid Eccentrotheca helenia sp. nov. from the Early Cambrian of South Australia. Palaeontology 54, 253-286 (2011).

46. Haug, J. T., Maas, A., Waloszek, D., Donoghue, P. C. J. \& Bengtson, S. A new species of Markuelia from the Middle Cambrian of Australia. Mem. Assoc. Australas. Palaeontol. 37, 303-313 (2009).

47. Hagadorn, J. W. et al. Cellular and subcellular structure of Neoproterozoic animal embryos. Science 314, 291-294 (2006)

48. Donoghue, P. C. J. et al. Synchrotron X-ray tomographic microscopy of fossil embryos. Nature 442, 680-683 (2006).

49. Yin, Z. et al. Nuclei and nucleoli in embryo-like fossils from the Ediacaran Weng'an Biota. Precambrian Res. 301, 145-151 (2017).

50. Maas, A. et al. The 'Orsten'-More than a Cambrian KonservatLagerstatte yielding exceptional preservation. Palaeoworld 15, 266-282 (2006).

51. Raff, E. C., Villinski, J. T., Turner, F. R., Donoghue, P. C. J. \& Raff, R. A. Experimental taphonomy shows the feasibility of fossil embryos. Proc. Natl Acad. Sci. USA 103, 5846-5851 (2006).

52. Gostling, N. J., Dong, X.-P. \& Donoghue, P. C. J. Ontogeny and taphonomy: and experimental taphonomy study of the development of the brine shrimp Artemia salina. Palaeontology 52, 169-186 (2009).

53. Marone, F., Studer, A., Billich, H., Sala, L. \& Stampanoni, M. Towards on-thefly data post-processing for real-time tomographic imaging at TOMCAT. Adv Struct. Chem. Imaging 3, 1 (2017).

\section{Acknowledgements}

We are grateful for the support with information on the regional geology of Mongolia and help during fieldwork and logistics by Anaad Chimidtseren, Ariuntsetseg Ganbat, and Munkh Ingder (Ulanbataar). The study was supported financially by Deutsche 
Forschungsgemeinschaft Bonn, Germany (grant no. STE814/5-1), Taishan Scholars Project (sdqn 201812069; Shandong Provincial People's Government), Natural Science Foundation of China (NSFC; nos. 41972026 and 41972108 to B.Y., no. 41950410566 to S.H., and no. 41672026 to D.L.), and the Natural Environmental Research Council grant (NE/P013678/1 to P.D.), part of the Biosphere Evolution, Transitions and Resilience (BETR) programme, which is co-funded by the NSFC. We also received funding from the European Union's Horizon 2020 research and innovation programme under grant agreement no. 730872, project CALIPSOplus, to access the X02DA TOMCAT beamline at the Swiss Light Source, time on which was funded by the Paul Scherrer Institute, Villigen, Switzerland through Project 20190071; we thank Federica Marone and Christian Schlepütz for their assistance at the beamline, as well as Stefan Bengtson and Jakob Vinther for discussion.

\section{Author contributions}

M.S. designed the project and carried out SEM study of the embryos and postembryonic developmental stages; P.D. conducted the srXTM measurements, M.S. the computed tomography. M.S., B.Y., S.H., and D.L. carried out fieldwork and discussed the results and manuscript. M.S. and P.D. led the writing of the manuscript, to which all authors contributed.

\section{Funding}

Open Access funding enabled and organized by Projekt DEAL.

\section{Competing interests}

The authors declare no competing interests.

\section{Additional information}

Supplementary information The online version contains supplementary material available at https://doi.org/10.1038/s41467-021-21264-7.

Correspondence and requests for materials should be addressed to M.S. or P.D.

Peer review information Nature Communications thanks Uwe Balthasar and the other, anonymous, reviewer(s) for their contribution to the peer review of this work.

Reprints and permission information is available at http://www.nature.com/reprints

Publisher's note Springer Nature remains neutral with regard to jurisdictional claims in published maps and institutional affiliations.

(c) (i) Open Access This article is licensed under a Creative Commons Attribution 4.0 International License, which permits use, sharing, adaptation, distribution and reproduction in any medium or format, as long as you give appropriate credit to the original author(s) and the source, provide a link to the Creative Commons license, and indicate if changes were made. The images or other third party material in this article are included in the article's Creative Commons license, unless indicated otherwise in a credit line to the material. If material is not included in the article's Creative Commons license and your intended use is not permitted by statutory regulation or exceeds the permitted use, you will need to obtain permission directly from the copyright holder. To view a copy of this license, visit http://creativecommons.org/ licenses/by/4.0/.

(c) The Author(s) 2021 